\title{
Age and Workplace Deviance: A Meta-Analytic Test of Two Mediating Mechanisms
}

\author{
Jan Luca Pletzer ${ }^{1}$, Janneke K. Oostrom ${ }^{2}$, \& Sven C. Voelpel ${ }^{3}$ \\ ${ }^{1}$ Erasmus University Rotterdam, the Netherlands \\ ${ }^{2}$ Vrije Universiteit Amsterdam, the Netherlands \\ ${ }^{3}$ Jacobs University Bremen, Germany
}

This manuscript is currently under review and will likely change before publication.

\begin{abstract}
Authors' Note
We thank Rosa van den Akker for her valuable help with data coding.

Please address correspondence concerning this article to Jan Luca Pletzer, Erasmus University Rotterdam, Burgemeester Oudlaan 50, 3062 PA Rotterdam. E-Mail: pletzer@essb.eur.nl
\end{abstract}




\begin{abstract}
In the current meta-analysis, we examine the relation between age and workplace deviance, and find a small but significant negative correlation $(\bar{\rho}=-.092, k=198)$. More importantly, we test two complementary mechanisms to help explain this relation. Specifically, based on the neo-socioanalytical model of personality change, we hypothesized that those Big Five personality domains that change with age and trait negative affect would mediate this relation. These hypotheses were supported, as the Big Five traits conscientiousness, agreeableness, and neuroticism, as well as trait negative affect simultaneously mediated the negative relation between age and workplace deviance. These findings highlight two important underlying mechanisms for this relation and suggest several opportunities for organizations to reduce the occurrence of workplace deviance. Further theoretical and practical implications as well as limitations and future research ideas are discussed.
\end{abstract}

Keywords: age, workplace deviance, counterproductive work behavior, personality, neo-socioanalytical model of personality change 
Age and Workplace Deviance: A Meta-Analytic Test of Two Mediating Mechanisms

Workplace deviance can have far-reaching and detrimental consequences for a number of important outcomes at work. For example, it is associated with a reduction of task and team performance (Dunlop \& Lee, 2004; Sackett, 2002), lower levels of organizational citizenship behavior (Dalal, 2005), and with higher turnover intentions and higher levels of burnout (Mackey et al., 2019). Organizations therefore want to prevent the occurrence of workplace deviance. As such, the prediction of workplace deviance is an important criterion in job selection contexts (Ones et al., 2007) and levels of workplace deviance are often used in employees' performance evaluations (Lievens et al., 2008; Welbourne et al., 1998). ${ }^{1}$

Previous research has shown that workplace deviance can be predicted by characteristics of the organizational environment (e.g., abusive supervision; Mitchell \& Ambrose, 2007) or by stable individual differences (e.g., personality; Berry, Ones, \& Sackett, 2007; Salgado, 2002). One important category of such stable individual differences are demographic characteristics. For example, Ng, Lam, and Feldman (2016) provided metaanalytic evidence that, on average, women behave in a slightly less deviant manner in the workplace than men. Another important demographic characteristic is age. Previous metaanalyses (Berry et al., 2007, 2012; Ng \& Feldman, 2008; Pletzer, 2021) have only indirectly addressed the relation between age and workplace deviance, but consistently find a small negative relation $(r=-.05$ to -.17$)$.

In the current meta-analysis, we aim to extend these findings by providing a comprehensive meta-analytic overview of the age-workplace deviance relation based on a much larger number of studies compared to previous meta-analyses. Importantly, we also answer Ng and Feldman's (2013) call for more research that addresses "why older workers may or may not perform at the same level as the younger workers" (p. 508). Although workplace deviance is not the same as job performance, it is an important behavior performed by employees that negatively contributes to their overall job performance and to the success 
of the organization. Workplace deviance is therefore widely regarded as an operationalization of job performance (Ng \& Feldman, 2008; Rotundo \& Sackett, 2002), and understanding why age relates negatively to workplace deviance is crucial to reduce levels of workplace deviance. We test two complementary mediating mechanisms for the relation between age and workplace deviance based on the neo-socioanalytical model of personality change (Roberts \& Wood, 2006), which holds that personality traits show small changes across the lifespan. Pletzer (2021) recently demonstrated that the HEXACO traits honesty-humility, emotionality, and conscientiousness mediate the relation between age and workplace deviance, but the more commonly used Big Five personality traits and trait negative affect have not yet been investigated as mediators of this relation. We aim to fill this gap. By doing so, we also provide meta-analytic estimates for all tested relations between age, Big Five personality traits, negative affect, and workplace deviance, except for the relations between the Big Five personality traits and negative affect. ${ }^{2}$

\section{Workplace Deviance}

Workplace deviance (or counterproductive work behavior) has been defined as "voluntary behavior that violates significant organizational norms and in so doing threatens the well-being of an organization, its members, or both" (Robinson \& Bennett, 1995, p. 556). Empirical evidence indicates that deviant behavior by employees is related to profit loss for organizations (Detert et al., 2007), and the direct and indirect costs of workplace deviance have been estimated to be in the billions for the US economy alone (e.g., National Retail Foundation, 2018; Needleman, 2008). Workplace deviance can be divided into subdimensions based on the target of the behaviors: the organization or its employees (Bennett $\&$ Robinson, 2000; Thrasher et al., 2020). Organizational deviance refers to behaviors that undermine the success of the organization, such as stealing, damaging company property, or leaving work early withour permission. Interpersonal deviance refers to behaviors directed toward members of the organization, such as gossiping or verbally abusing co-workers. As 
workplace deviance is considered a key problem for every organization (Porath \& Pearson, 2013), it is important for both researchers and practitioners to understand the extent to which workplace deviance is predicted by individual differences, including age. Furthermore, understanding the underlying mechanisms of the age-workplace relation is crucial because it can point towards opportunities for organizations to decrease the occurrence of workplace deviance and thereby improve their success.

\section{Neo-Socioanalytical Model of Personality Change}

Personality describes the set of stable traits that determine human feelings, thoughts, and behavior (Larsen \& Buss, 2005). It is most commonly assessed with the Big Five model (or Five-Factor Model; Goldberg, 1990; McCrae \& Costa, 1992), which posits that human personality can be described using the following five personality traits: openness to experience, conscientiousness, extraversion, agreeableness, and neuroticism. However, other personality traits, such as trait negative affect (Watson et al., 1988), also exist that are not sufficiently capured by the Big Five. Although personality is generally assumed to be relatively stable and even has a large genetic component (Jang et al., 1996), most scholars agree that personality can change in response to new experiences, challenges, and environments, even in adulthood (e.g., Soto, John, Gosling, \& Potter, 2011). Accordingly, the neo-socioanalytical model of personality change posits that personality characteristics, such as the Big Five personality traits (Goldberg, 1990; McCrae \& Costa, 1992) or trait negative affect (Watson et al., 1988), change slightly across the adult lifespan (Roberts \& Wood, 2006). A basic tenet of this model is that age-related changes in social roles, such as finding a partner, starting a family, or establishing one's career, are the driving mechanisms of personality development (i.e., the social investment principle; Roberts \& Wood, 2006). Social roles come with a set of societal expectations and contingencies, which promote a reward structure that calls for more normative patterns of personality traits (Roberts et al., 2005). Indeed, longitudinal, cross-sectional, and meta-analytic evidence shows pervasive normative 
development changes: Individuals score higher on conscientiousness and agreeableness, and lower on neuroticism and trait negative affect as they grow older (Charles et al., 2001; Roberts et al., 2006; Roberts \& Mroczek, 2008; Terracciano et al., 2005). Exactly these personality traits are strong predictors of workplace deviance (Berry et al., 2007, 2012; Pletzer et al., 2019; Salgado, 2002).

The Mediating Effects of Big Five Personality Traits. Conscientious individuals are hard-working, disciplined, and responsible, and should therefore refrain from acting deviantly because such behavior usually requires resources that could otherwise be spent on goal attainment (cf. activity regulation theory; Zijlstra, Roe, Leonora, \& Krediet, 1999). Agreeable individuals, who can be characterized as compassionate, social, and trusting, should refrain from acting deviantly because this would jeopardize their group belonging at work (cf. groupvalue theory; Lind \& Lissak, 1985). A similar reasoning can be applied to neurotic individuals, who might be more likely to act deviantly because they do not value group belonging as much and function less well in teams (Barrick et al., 1998). Meta-analytic average effect sizes support these expectations and demonstrate that those Big Five personality domains that change with age (i.e., conscientiousness, agreeableness, and neuroticism) also correlate with workplace deviance: Conscientiousness and agreeableness are negatively ( $r=-.31$ and $r=-.29$, respectively), whereas neuroticism is positively correlated with workplace deviance $(r=.16$; Pletzer et al., 2019). The average meta-analytic effect sizes for the relations of the other two Big Five personality domains, openness to experience and extraversion, with workplace deviance are not substantial $(r=-.04$ and $r=-$ .07 , respectively; Pletzer et al., 2019), but do show considerable variation. In other words, the correlations of openness to experience and extraversion with workplace deviance might be weaker, stronger, or even differ in direction depending on the situational context. However, in formulating our hypotheses we rely on the average meta-analytic correlations. According to the neo-socioanalytical model of personality change and research linking Big Five traits to 
levels of workplace deviance, we therefore expect that those personality domains that change with age mediate the relation between age and workplace deviance.

Hypothesis 1: The personality traits of conscientiousness, agreeableness, and neuroticism mediate the negative relation between age and workplace deviance.

The Mediating Effect of Trait Negative Affect. Trait negative affect predisposes individuals to experience higher levels of various negative affective events and mood states (Watson et al., 1988). To better understand the relation between age and trait negative affect, socio-emotional selectivity theory can be used in addition to the neo-socioanalytical model of personality change. Socio-emotional selectivity theory states that individuals become increasingly selective and spend more time on emotionally meaningful goals and activities as they grow older and their time horizons shrink (Carstensen, 1992). In line with this theory, research has consistently found that individuals develop a more pronounced preference for positive over negative emotions with increasing age (i.e., positivity effect; e.g., Mather \& Carstensen, 2005), a shift that already starts in middle-aged adults (i.e., 40-50 years old; Carstensen \& Mikels, 2005). Hence, middle-aged and older individuals are motivated to retain positive memories and to self-select into positive and meaningful situations. They also experience fewer interpersonal conflicts and less stress in response to conflicts if they occur (Birditt et al., 2005). In addition to this increased motivation to avoid negative emotions and conflicts, older (rather than younger) individuals have also been found to use more appropriate emotion regulation strategies due to their increased experience with emotional situations (Charles, 2010; Scheibe et al., 2015; Scheibe \& Carstensen, 2010). These emotion regulation skills decrease the likelihood of experiencing negative emotions even further (Mather \& Carstensen, 2005). In addition, age reduces memory for negative events (Charles et al., 2003). In line with the neo-socioanalytical model of personality change, such agerelated experiences can shape traits (Roberts \& Wood, 2006). Indeed, evidence consistently indicates that age is negatively related to trait negative affect (Charles et al., 2001; Mroczek \& 
Kolarz, 1998). Trait negative affect, in turn, is positively associated with workplace deviance (Bing et al., 2007; Dalal, 2005; Lee \& Allen, 2002; Spector \& Fox, 2002). Following this evidence, we hypothesize that:

Hypothesis 2: Trait negative affect mediates the negative relation between age and workplace deviance.

It should be mentioned, as a note of caution, that it is not entirely clear how distinct trait negative affect is from the Big Five traits. A recent meta-analysis (Anglim et al., 2020) demonstrated that negative affect correlates quite strongly with neuroticism $(r=.56)$, and also exhibits modest correlations with conscientiousness $(r=-.25)$, extraversion $(r=-.21)$, and agreeableness $(r=-.25)$. The meta-analytic correlation with openness to experience is also significant, but substantially weaker $(r=-.05)$. Given the conceptual and empirical overlap of the Big Five traits, and especially of neuroticism, with trait negative affect, it is crucial to examine the incremental mediation of one over the other as this will not only illuminate the link between age and workplace deviance but also contribute to the debate about how distinct the Big Five traits and trait negative affect are (Miller et al., 2009). We will therefore explore if the Big Five traits, and especially conscientiousness, agreeableness, and neuroticism, can incrementally explain the relation between age and workplace deviance over and above the mediating effect of trait negative affect.

\section{Method}

\section{Systematic Literature Search}

We conducted a systematic literature search on Web of Science in August 2019. We searched for articles containing the keywords workplace deviance, counterproductive work behavio*, organi*ational deviance, interpersonal deviance, or CWB in the title, abstract, or in the keywords. This way, we identied 1548 scientific articles. The first author examined all articles in full; 204 articles met our inclusion criteria (see below). In addition, we searched GoogleScholar and PsycInfo for more articles containing the abovementioned keywords. 
Finally, we examined prior meta-analyses published on the topic of workplace deviance (e.g., Berry et al., 2012, 2007; Ng \& Feldman, 2008; Ng et al., 2016) to see whether these contained any additional studies we might have missed in our literature search. This way, we identified 22 additional articles that were included.

Several criteria had to be met for a study to be included in our meta-analysis. First, the article had to report the correlation coefficient $(r)$ between age and workplace deviance, and the respective sample size $N$. Second, workplace deviance had to be measured at the individual level. Studies that reported levels of workplace deviance on a team or organizational level were excluded. Third, age had to be measured on a continuous scale. Studies that used a categorical measure of age were excluded. Based on these inclusion criteria, 284 independent samples and 506 effect sizes were included in the meta-analysis. Included articles were published between 1990 and 2019, with a median publication year of 2014. The first author and a student assistant, who had a Master's degree and who worked fulltime as a research assistant at the time of the coding, independently coded approximately half $(53.6 \%)$ of all effect size data (i.e., correlations, reliabilities, and sample sizes), which resulted in more than $97 \%$ absolute agreement. All inconsistencies in the codings were resolved after revisiting the article and discussing the respective coding. The first author then proceeded to code all additional effect sizes and study characteristics. The codings for each included effect size and the references of all included studies can be found in the supplementary materials.

\section{Definition of Variables}

Age. The sample mean age among all included independent samples ranged between 18.85 and 50.71 years, with an average age of 34.96 years $(S D=6.72)$.

Workplace deviance. In the current meta-analysis, we included all measures of workplace deviance. However, we did not include measures that assess the individual behaviors of absenteeism and lateness because these behaviors can also be determined by 
factors that do not violate organizational norms (e.g., being sick; Porter \& Steers, 1973). This inclusion criterion is in line with other meta-analyses about workplace deviance (e.g., Berry et al., 2012; Ng et al., 2016). Workplace deviance can be assessed as an overall construct which encompasses all deviant behaviors $(k=198)$. However, many articles differentiate between interpersonal and organizational deviance. Interpersonal workplace deviance includes all behaviors directed at other individuals in the organization (e.g., coworkers or supervisors) or at customers $(k=133)$. Examples of such behaviors are insulting a coworker or playing a prank on a coworker. Organizational workplace deviance includes all deviant behaviors directed at the organization in which an individual is employed $(k=150)$. We exploratorily examine if age relates differently to interpersonal and organizational workplace deviance.

Trait negative affect. Of the $k=30$ studies that assessed negative affect, $k=27$ used the Positive and Negative Affect Schedule (PANAS; Watson et al., 1988) and $k=3$ used the Job-Related Affective Well-Being Scale (JAWS; Katwyk, Fox, Specter, \& Kelloway, 2000). Although the JAWS is designed to measure state affect, scores on the JAWS are higly correlated with scores on the trait-based PANAS $(r=-.53$ between the JAWS and the negative affectivity subscale of the PANAS; Katwyk et al., 2000). We therefore decided to also include those studies using the JAWS.

Personality. The Big Five personality traits were assessed with various measures, such as the NEO-PI-R (Costa \& McCrae, 2008) or items from the International Personality Item Pool (IPIP; Goldberg et al., 2006). We also coded studies that used the HEXACO personality inventory for the domains conscientiousness, extraversion, and openness to experience because these domains are almost identical to those in the Big Five framework (Ashton \& Lee, 2007; Lee \& Ashton, 2004). We did not code studies using the HEXACO to assess the domains emotionality/neuroticism and agreeableness because there are important conceptual differences between the HEXACO and the Big Five for these domains (Ashton et al., 2014). This choice is justified by the finding that the relations of conscientiousness, 
extraversion, and openness to experience with workplace deviance do not differ between the Big Five and the HEXACO framework, while they do differ for emotionality/neuroticism and agreeableness (Pletzer et al., 2019).

\section{Data Analysis}

We used the Hunter and Schmidt (2014) type method for meta-analyses of correlation coefficients in a random-effects model. If a study reported only the correlations of age with interpersonal and organizational workplace deviance, but not with overall workplace deviance, we used composite formulas to aggregate the two correlations and corrected them with an aggregate reliability estimate calculated using Mosier's reliability formula (Hunter \& Schmidt, 2014). First, we provide sample size weighted effect size estimates to account for differential sampling error in the input correlations. Second, we corrected all correlation coefficients for unreliability in the criterion using internal reliabilities (i.e., Cronbach's alpha). If no reliabilities were provided in an article, we corrected the correlation using the weighted average reliability estimates for the respective workplace deviance from across all other studies included in this meta-analysis (see supplementary materials for these weighted average reliabilities). ${ }^{3} \mathrm{We}$ ran all further analyses on the corrected correlation unless specified otherwise. To assess heterogeneity of effect sizes, we computed a $Q$ statistic, tau, and an $I^{2}$ index using the Hunter and Schmidt (2014) estimator. The $I^{2}$ index indicates variability in the effect size based on real (rather than chance) differences between effect sizes. Benchmark values for the interpretation of $I^{2}$ are: $25 \%=$ low, $50 \%=$ medium, and $75 \%=$ high $($ Higgins et al., 2003). We also report the percentage of variance in $r$ that can be explained by unreliability. We test for publication bias using a rank correlation and regression test for funnel plot asymmetry (Begg \& Mazumdar, 1994; Egger et al., 1997). These indicators assess if effect sizes and precision differ systematically. If that is the case, publication bias is present in the data. Note that publication bias is unlikely to exist because the majority of studies included in this meta-analysis were not carried out to explicitly examine the relation between 
age and workplace deviance. All analyses were conducted using the metafor package in $\mathrm{R}$ (Viechtbauer, 2010).

Two-Stage Meta-Analytic Structural Equation Modeling. A two-stage randomeffects meta-analytic structural equation modeling (MASEM) (Cheung, 2014, 2015) was conducted to test Hypotheses 1 and 2. To do so, we additionally examined all included studies to identify whether a measure of either one of the Big Five personality domains (i.e., openness to experience, conscientiousness, extraversion, agreeableness, neuroticism) or of trait negative affect was included. We coded the effect sizes between age, workplace deviance (overall, interpersonal, organizational), and the respective mediator (see supplementary materials for the codings).

MASEM combines meta-analysis with structural equation modeling and consists of two stages. In the first stage, the correlations corrected for unreliability in both the predictor and the criterion (e.g., in conscientiousness and workplace deviance) between all variables from all primary studies are synthesized into an overall correlation matrix weighted by sample size. Whenever a study only reported correlations between interpersonal or organizational workplace deviance (and not for overall workplace deviance) and the mediator or age, we calculated a composite correlation with overall workplace deviance using the same procedures as described above. In the second stage, this meta-analytic correlation matrix is subjected to a structural equation model to test the mediation hypotheses. Using meta-analytic corrected correlations in such tertiary analysis is problematic given that the generalizability of our findings relies on the availability of other population values besides the meta-analytic correlations for all modeled relations (e.g., population estimates of variability; Tett, Hundley, \& Christiansen, 2017). Currently no solution exists how to best handle this issue, making it even more necessary to mention that the generalizability of our findings from the MASEM should be interpreted with caution. In the current study, we test six mediators (the Big Five traits and negative affect). If the indirect effect is significant and the direct effect decreases in 
magnitude, or becomes non-significant, a mediation is present. These analyses were conducted using the metaSEM package in $R$ (Cheung, 2014).

Comparing Mediating Mechanisms. To test the incremental mediation of the Big Five traits over and above the mediation of trait negative affect, we constructed an average correlation matrix including all correlations between age, all Big Five traits, trait negative affect, and workplace deviance (see supplementary materials). The correlations between the Big Five traits and negative affect were taken from Anglim et al. (2020); all other correlations were taken from the current meta-analysis, using the effect size estimate that was based on the largest sample size.

It is not possible to conduct a MASEM on such a constructed average correlation matrix because MASEM relies on both the correlation and the covariance matrix, which can be calculated only when pooling correlation matrices from primary studies. We therefore fit a structural equation model using the lavaan package in $R$ (Rosseel, 2012) on this average correlation matrix using the harmonic mean across all cells as the sample size (Viswesvaran \& Ones, 1995). To compare the mediating effects of trait negative affect with that of the Big Five traits, we first fit a model with only trait negative affect as a mediator to circumvent the unfair advantage that would exist if we would enter the Big Five traits first simply because they are more in number. We then examine if trait negative affect still mediates the relation between age and workplace deviance after the indirect effects via the Big Five traits are also included in the model. It is important to emphasize that this analytic approach treats the correlation matrix as a covariance matrix, which ignores the sampling uncertainty across studies (Cheung, 2020). More specifically, the values on the diagonal in a correlation matrix are always one, whereas they can have any non-negative value in a covariance matrix. This results in biased fitness indices and standard errors; standard errors are underestimated whereas test statistics are over-estimated. However, to the best of our knowledge, there is no more appropriate analytic method given the current data structure. 


\section{Results}

\section{Relation between Age and Workplace Deviance}

A small negative but significant weighted correlation between age and workplace deviance was found, $r=-.085,95 \%$ confidence interval $(\mathrm{CI}):-.102,-.068, p<.001, k=198$ (see Table 1). Correcting for unreliability in the criterion slightly strengthens the overall weighted effect size, $\bar{\rho}=-.092,95 \%$ CI: $-.111,-.073, p<.001, k=198$. Using these corrected correlations, high variability in the effect size distribution existed $\left(I^{2}=77.55, Q(197)=\right.$ $884.19, p<.001)$, which justifies the use of a random-effects model. Study effect sizes and precision differed significantly according to the regression test $(p=.038)$, indicating that publication bias might have influenced the results of the current meta-analysis. ${ }^{4}$ Note that these results are based on self-ratings if a study included both self- and other-ratings of workplace deviance to guarantee the independence of the included effect sizes. However, the overall weighted effect size does not change substantially when including other-ratings instead, $r=-.082, \bar{\rho}=-.089,95 \%$ CI: $-.108,-.070, p<.001, k=198$. Hence, we perform all MASEM analyses using self-ratings when both self- and other-ratings were included in a study and other-ratings when these were the only ratings included in a study.

\section{Moderators for the Age-Workplace Deviance Relation}

We also explored if the relation between age and workplace deviance is moderated by certain study characteristics (detailed results can be found in the supplementary materials). Organizational $(\bar{\rho}=-.102)$ and interpersonal workplace deviance $(\bar{\rho}=-.077)$ exhibited similar correlations with age, $Q(1)=2.457, p=.117$. Age correlated more strongly with self-ratings $(\bar{\rho}=-.103)$ than with other-ratings $(\bar{\rho}=-.041)$ of workplace deviance, $Q(1)=7.648, p=.006$. The correlation between age and workplace deviance did not differ when the Bennett and Robinson (2000) measure was used $(\bar{\rho}=-.096)$ compared to when another workplace deviance measure was used $(\bar{\rho}=-.088), Q(1)=0.181, p=.671$. 
$\mathrm{Ng}$ and Feldman (2008) found that the age-workplace deviance relation is more negative in samples with higher mean sample age. Using a much larger sample of studies, we replicate this finding: The age-workplace deviance relation is weakest in samples with a mean age 25 years or younger $(\bar{\rho}=-.059)$, followed by samples with a mean age of 25 to 39 years $(\bar{\rho}=-.103)$. The strongest correlation is observed in samples with a mean age of 40 years or older $(\bar{\rho}=-.127)$. The difference between these effect sizes estimates is significant, $Q(2)=$ $7.428, p=.024$. Using the mean sample age as a continuous moderator in a meta-regression also indicates that the age-workplace deviance becomes more negative for samples with higher mean age $(\beta=-.001, p=.037)$. We also examined if the percentage of female participants in a given study moderates the relation between age and workplace deviance, but did not find a significant moderation $(\beta=-.001, p=.058)$. The publication year (or the year in which a study was conducted for unpublished studies) did moderate the age-workplace deviance relation $(\beta=.010, p<.001)$, indicating that more recent studies find weaker effects.

Taken together, these findings suggest that the age-workplace deviance relation is not influenced by the form of or by the measure used to assess workplace deviance, and also not by the gender composition of the included samples. However, the age-workplace deviance relation is stronger later in life and when relying on self-reports of workplace deviance, and weaker in more recent studies.

\section{MASEM Mediation Test}

Table 2 shows the results of the separate meta-analyses conducted in the first stage of the MASEM. The overall weighted effect sizes found in this smaller subset of studies $(k=20$ - 36) resemble those found in the overall age-workplace deviance meta-analysis $(k=198)$ and in other meta-analyses of personality and workplace deviance (Berry et al., 2007, 2012; Pletzer et al., 2019; Salgado, 2002). Trait negative affect correlates positively with workplace deviance $(\bar{\rho}=.346)$, and only the subset of studies measuring trait negative affect find a 
slightly larger effect size for the age-workplace deviance relation $(\bar{\rho}=-.160$ compared to $\bar{\rho}=-$ .092 in the overall meta-analysis).

Table 3 shows the results of the MASEM used to test the hypotheses. The chi-square statistic for these mediation models is always 0 and the goodness-of-fit indices for structural equation models do not apply because all mediation models were saturated path models (Cheung, 2015). As hypothesized, trait negative affect, conscientiousness, agreeableness, and neuroticism all partially mediate the relation between age and workplace deviance (also see Figure 1 and 2). Only extraversion and openness to experience do not mediate the relation between age and workplace deviance (see Table 3).

When testing all Big Five traits in one model $(k=12, N=3,183)$, the three indirect effects for conscientiousness, agreeableness, and neuroticism are significant as well. The total effect of age on workplace deviance then is -.105 (95\% CI: $-.159,-.051)$, while the direct effect when adding the five mediators to the model becomes non-significant, -.051 (95\% CI: $.109, .010)$. The indirect effects are as follows: openness to experience: -.000 (95\% CI: -.005 , .005 ), conscientiousness: -.030 (95\% CI: -.059, -.010), extraversion: -.001 (95\% CI: -.109, $.010)$, agreeableness: -.018 (95\% CI: -.036, -.005), and neuroticism: -.011 (95\% CI: -.023, $.003)$. This indicates that the relation between age and workplace deviance is mediated by conscientiousness, agreeableness, and neuroticism, but not by extraversion and openness to experience. The indirect effect for conscientiousness is the strongest. Overall, Hypothesis 1 is partially and Hypothesis 2 is fully supported. ${ }^{5}$

\section{Incremental Mediation Analyses}

To examine the incremental mediation of the Big Five traits over and above the mediating effect of trait negative affect, we constructed one correlation matrix corrected for unreliability with all study variables (see supplementary materials), and fit different structural models using this correlation matrix. For all models, we used the harmonic mean sample size, which was 5727. 
In the first model, we only entered trait negative affect as a mediator of the relation between age and workplace deviance. Replicating the above results, trait negative affect partially mediates the relation between age and workplace deviance: The indirect effect ($.044 ; 95 \%$ CI: $-.053,-.035)$ and the direct effect (-.048; 95\% CI: $-.072,-.023)$ are both significant. In the second model, we only modelled indirect effects via all Big Five traits (and not via trait negative affect). Again replicating the above results, conscientiousness (-.022; 95\% CI: -.028, -.016), agreeableness (-.019; 95\% CI: -.025, -.012), and neuroticism (-.006; 95\% CI: -.009, -.003) mediated the relation between age and workplace deviance. Extraversion and openness to experience did not mediate this relation. The direct effect remained significant as well $(-.044 ; 95 \% \mathrm{CI}:-.068,-.020)$. In the third model, we simultaneously modelled indirect effects via trait negative affect and via all Big Five traits. The direct effect of age on workplace deviance was no longer significant (-.021; 95\% CI: $.044, .003)$. The indirect effects via conscientiousness (-.021; 95\% CI: -.027, -.015), agreeableness (-.016; 95\% CI: -.022, -.010), neuroticism (.007; 95\% CI: .004, .010), and trait negative affect (-.039; 95\% CI: -.048, -.031) were all significant. The indirect effects via extraversion and openness to experience were not significant. ${ }^{6}$ Note that the sign for the indirect effect of neuroticism is reversed when trait negative affect is also included compared to when it is not included in the model (.007 versus -.006; see above). This finding also holds when including only indirect effects via neuroticism and trait negative affect (excluding all other Big Five traits): The indirect effect via neuroticism remains positive $(.003 ; 95 \% \mathrm{CI}$ : $.001, .005)$, whereas the indirect via trait negative affect is negative (-.047; 95\% CI: -.057, $.037)$.

\section{Discussion}

Given the increasingly dominant role older workers play and will continue to play in the workforce, it is crucial to understand how organizations can reap the benefits of their characteristics and skills. In the current meta-analysis, which is based on more than 200 
studies, we contribute to that goal: We find a small negative correlation between age and workplace deviance. This finding corroborates prior scientific evidence demonstrating that older individuals are less likely to engage in deviant and criminal behavior (e.g., Sampson \& Laub, 1992), and more likely to engage in organizational citizenship behavior ( $\mathrm{Ng} \&$ Feldman, 2008; Pletzer, 2021) and to volunteer in general (Okun et al., 1998). More importantly, we do not only show that age relates to workplace deviance, but also test two complementary underlying mechanisms for this relation and therefore provide an answer to why age relates negatively to workplace deviance ( $\mathrm{Ng} \&$ Feldman, 2013). The current findings demonstrate that this negative relation can be explained using predictions based on the neo-socioanalytical model of personality change (Roberts \& Wood, 2006) and on the socio-emotional selectivity theory (Carstensen, 1992): Conscientiousness, agreeableness, and neuroticism as well as trait negative affect mediate the negative relation between age and workplace deviance. As such, age-related changes in personality traits can explain the negative relation between age and workplace deviance.

The neo-socioanalytical model of personality change posits that personality traits, including Big Five personality traits, change slightly across the adult lifespan (Roberts \& Wood, 2006). Those personality traits within the Big Five personality model that change over time (i.e., agreeableness, conscientiousness, and neuroticism; Roberts \& Mroczek, 2008; Roberts, Walton, \& Viechtbauer, 2006) are negatively related to levels of workplace deviance (Berry et al., 2007, 2012; Pletzer et al., 2019; Salgado, 2002). The results of the current metaanalysis confirm the hypothesis that these Big Five personality traits mediate the negative relation between age and workplace deviance. On average, extraversion and openness to experience do not relate to workplace deviance and also do not mediate the relation between age and workplace deviance. The findings for Big Five conscientiousness, neuroticism, extraversion, and openness to experience converge with those for their HEXACO counterparts by Pletzer (2021). In other words, both Big Five and HEXACO 
conscientiousness and neuroticism/emotionality mediate the relation between age and workplace deviance, whereas both Big Five and HEXACO extraversion and openness to experience do not mediate this relation. The findings do, however, differ for agreeableness: Big Five agreeableness mediates this relation, whereas HEXACO agreeableness does not. This difference can be explained by the fact that Big Five agreeableness captures variance associated with HEXACO honesty-humility, which does significantly mediate the ageworkplace deviance relation (Pletzer, 2021). This variance captured by Big Five agreeableness and HEXACO honesty-humility, but not by HEXACO agreeableness, apparently mediates the relation between age and workplace, resulting in the finding that only Big Five but not HEXACO agreeableness mediates the age-workplace deviance relation.

Another explanation for the age-workplace deviance relation is based on socioemotional selectivity theory (Carstensen, 1992), which states that as individuals age, they selfselect into emotionally meaningful and positive experiences, and possess lower levels of trait negative affect. For example, older, compared to younger, individuals focus more on goals related to generativity and emotions (Penningroth \& Scott, 2012), and show less confrontational behavior when having disagreements with others in the workplace (Davis et al., 2009). More importantly, older individuals have been found to appraise and respond to emotional events differently than younger individuals, and to regulate their emotional reaction to those events better (Scheibe \& Zacher, 2013). These age-related changes in emotional experiences at work, their behavioral consequences, and especially the subsequent reduced levels of trait negative affect are one of the explanatory mechanisms for our finding that levels of workplace deviance decrease with age. Individuals show lower levels of trait negative affect with increasing age, which is, in turn, associated with reduced levels of workplace deviance. These findings highlight a second important underlying process of the negative relation between age and workplace deviance. 
Interestingly, we found that both the Big Five traits (i.e., conscientiousness, agreeableness, and neuroticism) and trait negative affect simultaneously mediate the ageworkplace deviance relation, emphasizing that these two mediating mechanisms complement each other in explaining this relation. This finding has an important implication: It suggests that although neuroticism and negative affect are strongly related $(r=.56$; Anglim et al., 2020), they are not the same. This is further highlighted by the finding in the current metaanalysis that neuroticism and trait negative affect correlate differently with age $(\bar{\rho}=-.070$ and $\bar{\rho}=-.130$, respectively) and with workplace deviance $(\bar{\rho}=.202$ and $\bar{\rho}=.345$, respectively), and that the direction of the indirect effect of neuroticism is reversed when trait negative affect is also included in the model. This indicates that the specific variance in neuroticism that is not captured by trait negative affect relates negatively to workplace deviance. One possible explanation for this is the finding in previous research that the anxiety facet of neuroticism, which is not sufficiently captured by trait negative affect, does not significantly correlate with workplace deviance, whereas the anger facet, which is sufficiently captured by trait negative affect, correlates positively with workplace deviance (Hastings \& O’Neill, 2009). Future research should further examine cancellation and/or masking effects among the facets of neuroticism (Pletzer et al., 2020).

Related to this, trait negative affect seems to capture unique variance not captured by the Big Five traits that helps to further explain the relation between age and workplace deviance. In fact, the constructed correlation matrix shows that the Big Five traits explain $16.3 \%$ of the variance in workplace deviance, whereas adding trait negative affect as a predictor explains an additional $5.1 \%$ of the variance in workplace deviance. This indicates that trait negative affect also has incremental validity in explaining workplace deviance beyond the Big Five traits, which aligns with prior research suggesting that trait negative affect has incremental validity over and above the Big Five traits in predicting workaholism (Clark et al., 2010). 


\section{Practical Implications}

Overall, the current findings propose two important underlying mechanisms for the relation between age and workplace deviance. Understanding these mechanisms is crucial because, next to the scientific support for the two lifespan theories described above, it highlights important opportunities for practitioners to decrease the occurrence of workplace deviance and thereby improve work environments and organizational success. For example, various studies have shown that older individuals are disadvantaged in selection and employment decisions (e.g., Ahmed et al., 2012; Bendick et al., 1997; Duncan \& Loretto, 2004), which is unjustified from a strictly performance-based view (leaving ethical and moral views aside; Ng \& Feldman, 2008). In combination with the current findings, this suggests that organizations which avoid discriminating against older individuals in job selection might reap competitive benefits by observing lower levels of workplace deviance among their employees than those organizations which do discriminate against older individuals. Considering the costly nature of workplace deviance, even small decreases in workplace deviance are crucial for organizational success. For example, employee theft, which is only one specific form of workplace deviance, costs organizations $\$ 46.8$ billion in the USA alone. Although the amount of explained variance in workplace deviance using age as a predictor seems small at first sight $(0.85 \%$ based on $\rho=-.092)$, it could help organizations to save almost $\$ 400$ million when relying on the $\$ 46.8$ billion estimate mentioned above. One way for organizations to achieve such cost reductions is to take further steps to reduce age discrimination in employment decisions. For example, Finkelstein, Burke, and Raju (1995) suggested that highlighting job-relevant information and deemphasizing less important characteristics, such as age, have been shown to reduce age biases in hiring decisions.

Another opportunity to reduce levels of workplace deviance arises from the exploration of the two underlying mechanisms for the relation between age and workplace deviance because it helps researchers and practitioners to target the process by which age 
relates negatively to workplace deviance. Building on our finding that trait negative affect mediates the relation between age and workplace deviance and on the fact that trait and state negative affect are strongly related (e.g., Shallcross et al., 2013), organizations could try to reduce the experience of state negative affect, especially among younger workers, to possibly reduce levels of workplace deviance. Following trait activation theory (Tett \& Burnett, 2003) and situational strength theory (Meyer et al., 2010), organizations could also try to create organizational environments that reward the expression of those personality traits that relate negatively to workplace deviance, especially among younger workers who are more predisposed to act deviantly. The current findings suggest that such organizational interventions might lead to reduced levels of workplace deviance.

\section{Limitations and Future Research}

The current meta-analysis is not without limitations. First, most included studies use a cross-sectional design that does not allow an inference of causality. However, age is a characteristic that cannot be changed volitionally, rendering the use of it as a predictor of the Big Five traits, of trait negative affect, and subsequently of workplace deviance reasonable. A similar limitation pertains to the tested mediations, which are all based on correlational data. Given the vast amount of evidence on both Big Five traits (Berry et al., 2007, 2012; Pletzer et al., 2019; Salgado, 2002) and trait negative affect (e.g., Aquino et al., 1999; Chen, Chen, \& Liu, 2013; Lee \& Allen, 2002b; Samnani, Salamon, \& Singh, 2013) as predictors of workplace deviance, it is reasonable to assume that they determine workplace deviance. This argument is, however, based on the conceptual inference of trait-based causality, which holds that personality traits are relatively stable and therefore cannot be easily affected by behaviors (Larsen \& Buss, 2005), and not on more rigorous experimental control. As the neosocioanalytical model of personality change (Roberts \& Wood, 2006) suggests, investing in social roles, such as work and family roles, is one of the driving mechanisms of personality development. Thus, personality can also change in response to work events (for a review, see 
Tasselli, Kilduff, \& Landis, 2018). Accordingly, our findings could also indicate that acting deviantly at work changes one's personality traits. Indeed, Hudson and Roberts (2016) found that employees who act more deviantly over time also become less emotionally stable and less extraverted. Our findings should therefore be interpreted with caution.

Second, the age-workplace deviance relation was significantly stronger when workplace deviance was assessed through self- compared to other-reports, suggesting an alternative explanation for the negative relation between age and workplace deviance: As memory decreases with increasing age, especially when it comes to negative events (Charles et al., 2003), it might be that older individuals do not recall their deviant acts as well as younger individuals. However, it is unclear if this memory bias also applies in work settings. Future research should therefore corroborate our findings with more objective measures of workplace deviance that are not prone to be influenced by such biases and/or use diary studies to reduce the influence of recall bias (Ohly et al., 2010).

Third, there might be other variables, such as work attitudes (Rhodes, 1983) or goal orientations (Ebner et al., 2006), that should be examined as mediators before we fully understand why age relates negatively to workplace deviance.

Fourth, although our results suggest that the overall relation between age and workplace deviance is slightly negative, these results might not generalize across all situations given the high variability in the effect size distribution. For example, the $80 \%$ credibility interval for the age-workplace deviance relation $(-.239, .055)$ and for other examined relations included zero (e.g., for the age-neuroticism relation, -.205 to .065 , and for the neuroticismworkplace deviance relation, -.025 to .429 ), suggesting that some effect size estimates might actually be reversed in sign compared to the average observed meta-analytic correlation under certain circumstances. In other words, the $80 \%$ credibility interval for the age-workplace deviance indicates that a given observed correlation could be smaller than -.239 in $10 \%$ of the cases, or larger than .055 in another $10 \%$ of the cases. Given this high variability in some of 
the analyzed effect size distributions, it remains questionable if our mediation results would also hold up in cases where the correlation would be reversed in sign, and our findings should be interpreted in light of this limitation. The fact that some credibility intervals include zero also suggest that more moderator analyses are necessary to determine under which circumstances age relates negatively to workplace deviance, and possibly even under which circumstances a positive relation might be found. For example, age, and individual differences more generally, might be more strongly related to workplace deviance at higher levels in the organizational hierarchy because situations are then weaker, making traits more predictive of workplace deviance (Decelles et al., 2012; Galinsky et al., 2008). Similar findings were obtained for the relations of agreeableness and conscientiousness with job performance, which became stronger at higher levels of job autonomy (Barrick \& Mount, 1993). Future research should investigate if this also holds for the age-workplace deviance relation.

Fifth, publication bias might have influenced the results of the current meta-analysis. Although publication bias is unlikely to influence the current results because most studies were not carried out to explicitly examine the age-workplace deviance relation, some studies that were carried out to assess this relation might remain unpublished because of nonsignificant results. In addition, the selective reporting of significant results within primary studies might have biased the results of the current meta-analysis.

\section{Conclusion}

Age is negatively related to workplace deviance, and results of the current metaanalysis demonstrate that the Big Five domains conscientiousness, agreeableness, and neuroticism as well as trait negative affect can explain this negative relation. Our findings therefore contribute to a better understanding of the underlying mechanisms between individual differences and organizational behavior in general and between age and workplace deviance spcifically. As older workers are still disadvantaged in employment and promotion 
decisions (e.g., Ahmed, Andersson, \& Hammarstedt, 2012), we hope that our findings help organizations realize the competitive benefits of fairer selection procedures. 


\section{References}

Ahmed, A. M., Andersson, L., \& Hammarstedt, M. (2012). Does age matter for employability? A field experiment on ageism in the Swedish labour market. Applied Economics Letters, 19, 403-406. https://doi.org/10.1080/13504851.2011.581199

Anglim, J., Horwood, S., Smillie, L. D., Marrero, R. J., \& Wood, J. K. (2020). Predicting psychological and subjective well-being from personality: A meta-analysis.

Psychological Bulletin, 146, 279-323. https://doi.org/10.1037/bul0000226

Aquino, K., Lewis, M. U., \& Bradfield, M. (1999). Justice constructs, negative affectivity, and employee deviance: A proposed model and empirical test. Journal of Organizational Behavior, 20, 1073-1091. https://doi.org/10.1002/(SICI)1099-

1379(199912)20:7<1073::AID-JOB943>3.0.CO;2-7

Ashton, M. C., \& Lee, K. (2007). Empirical, theoretical, and practical advantages of the HEXACO model of personality structure. Personality and Social Psychology Review, 11, 150-166. https://doi.org/10.1177/1088868306294907

Ashton, M. C., Lee, K., \& De Vries, R. E. (2014). The HEXACO Honesty-Humility, Agreeableness, and Emotionality factors: A review of research and theory. Personality and Social Psychology Review, 18, 139-152. https://doi.org/10.1177/1088868314523838

Barrick, M. R., \& Mount, M. K. (1993). Autonomy as a moderator of the relationships between the Big Five personality dimensions and job performance. Journal of Applied Psychology, 78, 111-118. https://doi.org/10.1037/0021-9010.78.1.111

Barrick, M. R., Neubert, M. J., Mount, M. K., \& Stewart, G. L. (1998). Relating member ability and personality to work-team processes and team effectiveness. Journal of Applied Psychology, 83, 377-391. https://doi.org/10.1037/0021-9010.83.3.377

Begg, C. B., \& Mazumdar, M. (1994). Operating characteristics of a rank correlation test for publication bias. Biometrics, 50, 1088-1101. https://doi.org/10.2307/2533446

Bendick, M. J., Jackson, C. W., \& Horacio, J. (1997). Employment discrimination against 
older workers. Journal of Aging \& Social Policy, 8, 37-41.

https://doi.org/10.1300/J031v08n04

Bennett, R. J., \& Robinson, S. L. (2000). Development of a measure of workplace deviance. Journal of Applied Psychology, 85, 349-360. https://doi.org/10.1037//00219010.85 .3 .349

Berry, C. M., Carpenter, N. C., \& Barratt, C. L. (2012). Do other-reports of counterproductive work behavior provide an incremental contribution over self-reports? A meta-analytic comparison. Journal of Applied Psychology, 97, 613-636.

https://doi.org/10.1037/a0026739

Berry, C. M., Ones, D. S., \& Sackett, P. R. (2007). Interpersonal deviance, organizational deviance, and their common correlates: A review and meta-analysis. Journal of Applied Psychology, 92, 410-424. https://doi.org/10.1037/0021-9010.92.2.410

Bing, M. N., Stewart, S. M., Davison, H. K., Green, P. D., McIntyre, M. D., \& James, L. R. (2007). An integrative typology of personality assessment for aggression: implications for predicting counterproductive workplace behavior. Journal of Applied Psychology, 92, 722-744. https://doi.org/10.1037/0021-9010.92.3.722

Birditt, K. S., Fingerman, K. L., \& Almeida, D. M. (2005). Age differences in exposure and reactions to interpersonal tensions: A daily diary study. Psychology and Aging, 20, 330340. https://doi.org/10.1037/0882-7974.20.2.330

Carstensen, L. L. (1992). Social and emotional patterns in adulthood: Support for socioemotional selectivity theory. Psychology and Aging, 7, 331-338. https://doi.org/10.1037/0882-7974.7.3.331

Carstensen, L. L., \& Mikels, J. A. (2005). At the intersection of emotiona and cognition. Current Directions in Psychological Science, 14, 117-121. https://doi.org/10.1111/j.0963-7214.2005.00348.x

Charles, S. T. (2010). Strength and vulnerability integration: A model of emotional well-being 
across adulthood. Psychological Bulletin, 136, 1068-1091.

https://doi.org/10.1037/a0021232

Charles, S. T., Mather, M., \& Carstensen, L. L. (2003). Aging and emotional memory: The forgettable nature of negative images for older adults. Journal of Experimental Psychology: General, 132, 310-324. https://doi.org/10.1037/0096-3445.132.2.310

Charles, S. T., Reynolds, C. A., \& Gatz, M. (2001). Age-related differences and change in positive and negative affect over 23 years. Journal of Personality and Social Psychology, 80, 136-151. https://doi.org/10.1037/0022-3514.80.1.136

Chen, C.-C., Chen, M. Y.-C., \& Liu, Y.-C. (2013). Negative affectivity and workplace deviance: The moderating role of ethical climate. The International Journal of Human Resource Management, 24, 2894-2910. https://doi.org/10.1080/09585192.2012.753550

Cheung, M. W.-L. (2014). Fixed- and random-effects meta-analytic structural equation modeling: Examples and analyses in R. Behavior Research Methods, 46, 29-40. https://doi.org/10.3758/s13428-013-0361-y

Cheung, M. W.-L. (2015). Meta-Analysis: A Structural Equation Modeling Approach. John Wiley \& Sons, Ltd.

Cheung, M. W.-L. (2020). Meta-analytic structural equation modeling. In Oxford Research Encyclopedia of Business and Management: Vol. Pre-print (Issues 1-32, pp. 351-360).

Clark, M. A., Lelchook, A. M., \& Taylor, M. L. (2010). Beyond the Big Five: How narcissism, perfectionism, and dispositional affect relate to workaholism. Personality and Individual Differences, 48, 786-791. https://doi.org/10.1016/j.paid.2010.01.013

Costa, P. T., \& McCrae, R. R. (2008). The revised NEO Personality Inventory (NEO-PI-R). In G. J. Boyle, G. Matthews, \& D. H. Saklofske (Eds.), The SAGE handbook of personality theory and assessment, Vol. 2. Personality measurement and testing (pp. 179-198). Sage Publications, Inc.

Dalal, R. S. (2005). A meta-analysis of the relationship between organizational citizenship 
behavior and counterproductive work behavior. Journal of Applied Psychology, 90, 1241-1255. https://doi.org/10.1037/0021-9010.90.6.1241

Davis, M. H., Kraus, L. A., \& Capobianco, S. (2009). Age differences in responses to conflict in the workplace. International Journal of Aging and Human Development, 68, 339-355. https://doi.org/10.2190/AG.68.4.d

Decelles, K. A., Derue, D. S., Ceranic, T. L., \& Margolis, J. D. (2012). Does power corrupt or enable? When and why power facilitates self-interested behavior. Journal of Applied Psychology, 97, 681-689. https://doi.org/10.1037/a0026811

Detert, J. R., Treviño, L. K., Burris, E. R., \& Andiappan, M. (2007). Managerial modes of influence and counterproductivity in organizations: A longitudinal business-unit-level investigation. Journal of Applied Psychology, 92, 993-1005. https://doi.org/10.1037/0021-9010.93.2.328

Duncan, C., \& Loretto, W. (2004). Never the right age? Gender and age based discrimination in employment. Gender, Work and Organization, 11, 95-114. https://doi.org/10.1111/j.1468-0432.2004.00222.x

Dunlop, P. D., \& Lee, K. (2004). Workplace deviance, organizational citizenship behavior, and business unit performance: The bad apples do spoil the whole barrel. Journal of Organizational Behavior, 25, 67-80. https://doi.org/10.1002/job.243

Ebner, N. C., Freund, A. M., \& Baltes, P. B. (2006). Developmental changes in personal goal orientation from young to late adulthood: From striving for gains to maintenance and prevention of losses. Psychology and Aging, 21, 664-678. https://doi.org/10.1037/08827974.21.4.664

Egger, M., Davey Smith, G., Schneider, M., \& Minder, C. (1997). Bias in meta-analysis detected by a simple, graphical test. British Medical Journal, 315, 629-634. https://doi.org/10.1136/bmj.315.7109.629

Finkelstein, L. M., Burke, M. J., \& Raju, M. S. (1995). Age discrimination in simulated 
employment contexts: An integrative analysis. Journal of Applied Psychology, 80, 652663. https://doi.org/10.1037/0021-9010.80.6.652

Galinsky, A. D., Magee, J. C., Gruenfeld, D. H., Whitson, J. A., \& Liljenquist, K. A. (2008). Power reduces the press of the situation: Implications for creativity, conformity, and dissonance. Journal of Personality and Social Psychology, 95, 1450-1466. https://doi.org/10.1037/a0012633

Goldberg, L. R. (1990). An alternative " description of personality ": The Big-Five Factor structure. Journal of Personality and Social Psychology, 59, 1216-1229. https://doi.org/10.1037/0022-3514.59.6.1216

Goldberg, L. R., Johnson, J. A., Eber, H. W., Hogan, R., Ashton, M. C., Cloninger, C. R., \& Gough, H. G. (2006). The international personality item pool and the future of publicdomain personality measures. Journal of Research in Personality, 40, 84-96. https://doi.org/10.1016/j.jrp.2005.08.007

Hastings, S. E., \& O’Neill, T. A. (2009). Predicting workplace deviance using broad versus narrow personality variables. Personality and Individual Differences, 47, 289-293. https://doi.org/10.1016/j.paid.2009.03.015

Henle, C. A., Giacalone, R. A., Jurkiewicz, C. L., Henle, C. A., Giacalone, R. A., \& Jurkiewicz, C. L. (2005). The role of ethical Ideology in workplace deviance. Journal of Business Ethics, 56, 219-230. https://doi.org/10.1007/s10551-004-2779-8

Higgins, J. P. T., Thompson, S. G., Deeks, J. J., \& Altman, D. G. (2003). Measuring inconsistency in meta-analysis. British Medical Journal, 327, 557-560. https://doi.org/10.1136/bmj.327.7414.557

Hudson, N. W., \& Roberts, B. W. (2016). Social investment in work reliably predicts change in conscientiousness and agreeableness: A direct replication and extension of Hudson, Roberts, and Lodi-Smith (2012). Journal of Research in Personality, 60, 12-23. https://doi.org/10.1016/j.jrp.2015.09.004 
Hunter, J. E., \& Schmidt, F. L. (2014). Methods of meta-analysis: Correcting error and bias in research findings. Sage Publications.

Jang, K. L., Livesley, W. J., \& Vemon, P. A. (1996). Heritability of the Big Five personality dimensions and their facets: A twin study. Journal of Personality, 64, 577-591. https://doi.org/10.1111/j.1467-6494.1996.tb00522.x

Katwyk, P. T. Van, Fox, S., Specter, P. E., \& Kelloway, E. K. (2000). Using the job-related affective well-being scale (JAWS) to investige affective responses to work stressors. Journal of Occupational Health Psychology, 5, 219-230. https://doi.org/10.1037//10768998.5.2.219

Larsen, R. J., \& Buss, D. M. (2005). Personality psychology: Domains of knowledge about human nature (2nd Ed.). McGraw Hill.

Lee, K., \& Allen, N. J. (2002). Organizational citizenship behavior and workplace deviance: The role of affect and cognition. Journal of Applied Psychology, 87, 131-142. https://doi.org/10.1037//0021-9010.87.1.131

Lee, K., \& Ashton, M. C. (2004). Psychometric properties of the HEXACO personality inventory. Multivariate Behavioral Research, 39, 303-328. https://doi.org/10.1207/s15327906mbr3902

Lievens, F., Conway, J. M., \& De Corte, W. (2008). The relative importance of task, citizenship and counterproductive performance to job performance ratings: Do rater source and team-based culture matter? Journal of Occupational and Organizational Psychology, 81, 11. https://doi.org/10.1348/096317907X182971

Lind, E. A., \& Lissak, R. I. (1985). Apparent impropriety and procedural fairness judgments. Journal of Experimental Social Psychology, 21, 19-29. https://doi.org/10.1016/0022$1031(85) 90003-4$

Mackey, J. D., McAllister, C. P., Parker Ellen III, B., \& Carson, J. E. (2019). A meta-analysis of interpersonal and organizational workplace deviance research. Journal of 
Management, in press, 1-26. https://doi.org/10.1177/0149206319862612

Mather, M., \& Carstensen, L. L. (2005). Aging and motivated cognition: The positivity effect in attention and memory. Trends in Cognitive Sciences, 9, 496-502. https://doi.org/10.1016/j.tics.2005.08.005

McCrae, R. R., \& Costa, P. T. (1992). Personality trait structure as a human universal. American Psychologist, 52, 509-516. https://doi.org/10.1037/0003-066X.52.5.509

Meyer, R. D., Dalal, R. S., \& Hermida, R. (2010). A review and synthesis of situational strength in the organizational sciences. Journal of Management, 36, 121-140. https://doi.org/10.1177/0149206309349309

Miller, D. J., Vachon, D. D., \& Lynam, D. R. (2009). Neuroticism, negative affect, and negative affect instability: Establishing convergent and discriminant validity using ecological momentary assessment. Personality and Individual Differences, 47, 873-877. https://doi.org/10.1016/j.paid.2009.07.007

Mitchell, M. S., \& Ambrose, M. L. (2007). Abusive supervision and workplace deviance and the moderating effects of negative reciprocity beliefs. Journal of Applied Psychology, 92, 1159-1168. https://doi.org/10.1037/0021-9010.92.4.1159

Mroczek, D. K., \& Kolarz, C. M. (1998). The effect of age on positive and negative affect: A developmental perspective. Journal of Personality and Social Psychology, 75, 13331349. https://doi.org/10.1037/0022-3514.75.5.1333

National Retail Foundation. (2018). NRF/University of Florida survey says retail 'shrink' decreased to $\$ 46.8$ billion in 2017. National Retail Foundation. https://nrf.com/mediacenter/press-releases/nrfuniversity-florida-survey-says-retail-shrink-decreased-468billion

Needleman, S. E. (2008). Businesses Say Theft by Their Workers Is Up. The Wall Street Journal.

Ng, T. W. H., \& Feldman, D. C. (2008). The relationship of age to ten dimensions of job 
performance. Journal of Applied Psychology, 93, 392-423. https://doi.org/10.1037/00219010.93 .2 .392

Ng, T. W. H., \& Feldman, D. C. (2013). How do within-person changes due to aging affect job performance? Journal of Vocational Behavior, 83, 500-513. https://doi.org/10.1016/j.jvb.2013.07.007

Ng, T. W. H., Lam, S. S. K., \& Feldman, D. C. (2016). Organizational citizenship behavior and counterproductive work behavior: Do males and females differ? Journal of Vocational Behavior, 93, 11-32. https://doi.org/10.1016/j.jvb.2015.12.005

Ohly, S., Sonnentag, S., Niessen, C., \& Zapf, D. (2010). Diary studies in organizational research: An introduction and some practical recommendations. Journal of Personnel Psychology, 9, 79-93. https://doi.org/10.1027/1866-5888/a000009

Okun, M. A., Barr, A., \& Herzog, A. R. (1998). Motivation to volunteer by older adults: A test of competing measurement models. Psychology and Aging, 13, 608-621. https://doi.org/10.1037/0882-7974.13.4.608

Ones, D. S., Dilchert, S., Viswesvaran, C., \& Judge, T. A. (2007). In support of personality assessment in organizational settings. Journal of Applied Psychology, 60, 995-1027. https://doi.org/10.1111/j.1744-6570.2007.00099.x

Penningroth, S. L., \& Scott, W. D. (2012). Age-related differences in goals: Testing predictions from selection, optimization, and compensation theory and socioemotional selectivity theory. The International Journal of Aging and Human Development, 74, 87111. https://doi.org/10.2190/AG.74.2.a

Pletzer, J. L. (2021). Why older employees engage in less counterproductive work behavior and in more organizational citizenship behavior: Examining the role of the HEXACO personality traits. Personality and Individual Differences. https://doi.org/10.1016/j.paid. 2020.110550

Pletzer, J. L., Bentvelzen, M., Oostrom, J. K., \& De Vries, R. E. (2019). A meta-analysis of 
the relations between personality and workplace deviance: Big Five versus HEXACO. Journal of Vocational Behavior, 112, 369-383. https://doi.org/10.1016/j.jvb.2019.04.004

Pletzer, J. L., Oostrom, J. K., Bentvelzen, M., \& De Vries, R. E. (2020). Comparing domainand facet-level relations of the HEXACO personality model with workplace deviance: A meta-analysis. Personality and Individual Differences, 152, 109539. https://doi.org/10.1016/j.paid.2019.109539

Porath, C., \& Pearson, C. (2013). The price of incivility. Harvard Business Review, 91, 114121.

Porter, L. W., \& Steers, R. M. (1973). Organizational, work, and personal factors in employee turnover and absenteeism. Psychological Bulletin, 80(2), 151-176.

Rhodes, S. R. (1983). Age-related differences in work attitudes and behavior: A review and conceptual analysis. Psychological Bulletin, 93, 328-367. https://doi.org/10.1037/00332909.93.2.328

Roberts, B. W., \& Mroczek, D. (2008). Personality trait change in adulthood. Current Directions in Psychological Science, 17, 31-35. https://doi.org/10.1111/j.14678721.2008.00543.x

Roberts, B. W., Walton, K. E., \& Viechtbauer, W. (2006). Patterns of mean-level change in personality traits across the life course: A meta-analysis of longitudinal studies. Psychological Bulletin, 132, 1-25. https://doi.org/10.1037/0033-2909.132.1.1

Roberts, B. W., \& Wood, D. (2006). Personality development in the context of the neosocioanalytic model of personality. In D. K. Mroczek \& T. D. Little (Eds.), Handbook of personality development. Lawrence Erlbaum Associates Publishers.

Roberts, B. W., Wood, D., \& Smith, J. L. (2005). Evaluating Five Factor Theory and social investment perspectives on personality trait development . Journal of Research in Personality, 39, 166-184. https://doi.org/10.1016/j.jrp.2004.08.002

Robinson, S. L., \& Bennett, R. J. (1995). A typology of deviant workplace behaviors: A 
multidimensional scaling study. Academy of Management Journal, 38, 555-572. https://doi.org/10.2307/256693

Rosseel, Y. (2012). lavaan: An R package for structural equation modeling. Journal of Statistical Software, 48(2), 1-36.

Rotundo, M., \& Sackett, P. R. (2002). The relative importance of task, citizenship, and counterproductive performance to global ratings of job performance: A policy-capturing approach. Journal of Applied Psychology, 87, 66-80. https://doi.org/10.1037/00219010.87 .1 .66

Sackett, P. R. (2002). The structure of counterproductive work behaviors: Dimensionality and relationships with facets of job performance. International Journal of Selection and Assessment, 10, 5-11. https://doi.org/10.1111/1468-2389.00189

Salgado, J. F. (2002). The big five personality dimensions and counterproductive behaviors. International Journal of Selection and Assessment, 10, 117-125. https://doi.org/10.1111/1468-2389.00198

Samnani, A. K., Salamon, S. D., \& Singh, P. (2013). Negative affect and counterproductive workplace behavior: The moderating role of moral disengagement and gender. Journal of Business Ethics, 1-10. https://doi.org/10.1007/s10551-013-1635-0

Sampson, R. J., \& Laub, J. H. (1992). Crime and deviance in the life course. Annual Review of Sociology, 18, 63-84. https://doi.org/10.1146/annurev.so.18.080192.000431

Scheibe, S., \& Carstensen, L. L. (2010). Emotional aging: Recent findings and future trends. Journal of Gerontology: Psychological Sciences, 65B, 135-144. https://doi.org/10.1093/geronb/gbp132.

Scheibe, S., Sheppes, G., \& Staudinger, U. M. (2015). Distract or reappraise? Age-related differences in emotion-regulation choice. Emotion, 15, 677-681. https://doi.org/http://dx/doi.org/10.1037/a0039246

Scheibe, S., \& Zacher, H. (2013). A lifespan perspective on emotion regulation, stress, and 
well-being in the workplace. Research in Occupational Stress and Well Being, 11, 163193. https://doi.org/10.1108/S1479-3555(2013)0000011010

Shallcross, A. J., Ford, Brett, Q., Floerke, V. A., \& Mauss, I. B. (2013). Getting better with age: The relationship between age, acceptance, and negative affect. Journal of Personality and Social Psychology, 104, 734-749. https://doi.org/10.1037/a0031180

Soto, C. J., John, O. P., Gosling, S. D., \& Potter, J. (2011). Age differences in personality traits from 10 to 65: Big Five domains and facets in a large cross-sectional sample. Journal of Personality and Social Psychology, 100, 330-348.

https://doi.org/10.1037/a0021717

Spector, P. E., \& Fox, S. (2002). An emotion-centered model of voluntary work behavior: Some parallels between counterproductive work behavior and organizational citizenship behavior. Human Resource Management Review, 12, 1-24. https://doi.org/10.1016/S1053-4822(02)00049-9

Tasselli, S., Kilduff, M., \& Landis, B. (2018). Personality change: Implications for organizational behavior. Academy of Management Annals, 12, 467-493. https://doi.org/10.5465/annals.2016.0008

Terracciano, A., McCrae, R. R., Brant, L. J., \& Costa, P. T. (2005). Hierarchical linear modeling analyses of NEO-PI-R scales in the Baltimore longitudinal study of aging. Psychology and Aging, 20, 493-506. https://doi.org/10.1037/0882-7974.20.3.493

Tett, R. P., \& Burnett, D. D. (2003). A personality trait-based interactionist model of job performance. Journal of Applied Psychology, 88, 500-517. https://doi.org/10.1037/00219010.88 .3 .500

Tett, R. P., Hundley, N. A., \& Christiansen, N. D. (2017). Meta-analysis and the myth of generalizability. Industrial and Organizational Psychology: Perspectives on Science and Practice, 10, 421-456. https://doi.org/10.1017/iop.2017.26

Thrasher, G. R., Krenn, D. K., \& Marchiondo, L. A. (2020). Are counter-productive 
workplace behaviors and workplace deviance parallel constructs? A meta-analytic test of a common practice. Occupational Health Science. https://doi.org/10.1007/s41542-020$00065-2$

Viechtbauer, W. (2010). Conducting meta-analyses in R with the metafor package. Journal of Statistical Software, 36, 1-48. https://doi.org/10.1103/PhysRevB.91.121108

Viswesvaran, C., \& Ones, D. S. (1995). Theory testing: Combining psychometric metaanalysis and structural equation modeling. Personnel Psychology, 48, 865-885. https://doi.org/10.1111/j.1744-6570.1995.tb01784.x

Watson, D., Clark, L. A., \& Tellegen, A. (1988). Development and validation of brief measures of positive and negative affect: The PANAS scales. Journal of Personality and Social Psychology, 54, 1063-1070. https://doi.org/10.1037/0022-3514.54.6.1063

Welbourne, T. M., Johnson, D. E., \& Erez, A. (1998). The role-based performance scale: Validity analysis of a theory-based measure. Academy of Management Journal, 41, 540555. https://doi.org/10.2307/256941

Zijlstra, F. R. H., Roe, R. A., Leonora, A. B., \& Krediet, I. (1999). Temporal factors in mental work: Effects of interrupted activities. Journal of Occupational and Organizational Psychology, 72, 163-185. https://doi.org/10.1348/096317999166581 


\section{Tables}

Table 1

Overall meta-analytic results for the relation between age and workplace deviance

\begin{tabular}{|c|c|c|c|c|c|c|c|c|c|c|c|c|c|c|c|}
\hline & \multicolumn{10}{|c|}{ Overall Effect Size } & \multicolumn{3}{|c|}{ Heterogeneity } & \multicolumn{2}{|c|}{ Publication Bias } \\
\hline ID & 133 & 42,657 & -.071 & .100 & -.077 & .108 & 26.46 & $-.099,-.056$ & $-.215, .061$ & $<.001$ & 567.25 & .107 & 76.46 & .060 & .033 \\
\hline
\end{tabular}

Note. $k=$ cumulative number of studies; $N=$ cumulative sample size; $r=$ sample size weighted correlation; $\mathrm{SD} r=\operatorname{standard}$ deviation for $r ; \bar{\rho}=$ correlation corrected for unreliability; $\mathrm{SD} \bar{\rho}=$ standard deviation for $\bar{\rho} ; \%$ Var $=$ percentage of variance attributable to unreliability; $95 \% \mathrm{CI}=95 \%$ confidence interval for $\bar{\rho} ; 80 \% \mathrm{CrI}=80 \%$ credibility interval for $\bar{\rho} ; p=\mathrm{p}$-value for $\overline{\bar{\rho}} ; Q, T$, and $I^{2}=$ indices of heterogeneity for $\bar{\rho}$; Rank $p=p$-value for the rank correlation test of funnel plot asymmetry using $\bar{\rho} ; \operatorname{Reg}_{p}=p$-value for the regression test of funnel plot asymmetry using $\bar{\rho}$; WD $=$ overall workplace deviance; ID = interpersonal workplace deviance, $\mathrm{OD}=$ organizational workplace deviance. 
Table 2

Meta-analytic results used to test the mediation hypotheses

\begin{tabular}{|c|c|c|c|c|c|c|c|c|}
\hline & $r$ & $\mathrm{SD} r$ & $\bar{\rho}$ & $\mathrm{SD} \rho$ & $95 \% \mathrm{CI}$ & $80 \% \mathrm{CrI}$ & $T$ & $I^{2}$ \\
\hline \multicolumn{9}{|c|}{ Age - Negative Affect - WD $(k=32, N=10,709)$} \\
\hline Age - WD & $-.143 * *$ & .101 & $-.153 * *$ & .109 & $-.196,-.111$ & $-.292,-.014$ & .106 & 79.65 \\
\hline \multicolumn{9}{|c|}{ Age - Openness - WD $(k=20, N=5,425)$} \\
\hline Age $-\mathrm{O}$ & .028 & .091 & .031 & .107 & $-.023, .086$ & $-.106, .169$ & .103 & 73.96 \\
\hline Age - WD & $-.096 * *$ & .111 & $-.104 * *$ & .122 & $-.163,-.044$ & $-.260, .053$ & .118 & 79.06 \\
\hline Age $-\mathrm{C}$ & $.091 * *$ & .106 & $.103 * *$ & .125 & $.058, .148$ & $-.057, .263$ & .123 & 83.01 \\
\hline Age - WD & $-.098 * *$ & .093 & $-.106 * *$ & .105 & $-.146,-.067$ & $-.241, .028$ & .103 & 77.38 \\
\hline $\mathrm{C}-\mathrm{WD}$ & $-.268 * *$ & .129 & $-.321 * *$ & .163 & $-.377,-.266$ & $-.529,-.113$ & .160 & 91.34 \\
\hline \multicolumn{9}{|c|}{ Age - Extraversion - WD $(k=20, N=5,425)$} \\
\hline Age $-E$ & -.026 & .113 & -.027 & .125 & $-.088, .034$ & $-.187, .133$ & .121 & 79.56 \\
\hline Age - WD & $-.096 * *$ & .110 & $-.104 * *$ & .121 & $-.163,-.044$ & $-.259, .052$ & .117 & 78.92 \\
\hline$E-W D$ & -.058 & .132 & -.065 & .158 & $-.139, .008$ & $-.267, .136$ & .153 & 86.32 \\
\hline \multicolumn{9}{|c|}{ Age - Neuroticism - WD $(k=22, N=7,219)$} \\
\hline Age $-\mathrm{N}$ & $-.066^{* *}$ & .059 & $-.070 * *$ & .069 & $-.108,-.033$ & $-.205, .065$ & .066 & 58.49 \\
\hline Age - WD & $-.074 * *$ & .057 & $-.081 * *$ & .067 & $-.119,-.044$ & $-.212, .049$ & .064 & 56.76 \\
\hline $\mathrm{N}-\mathrm{WD}$ & $.177 * *$ & .089 & $.202 * *$ & .116 & $.148, .256$ & $-.025, .429$ & .113 & 81.84 \\
\hline
\end{tabular}

Note. $k=$ cumulative number of studies; $N=$ cumulative sample size; $r=$ sample-size weighted mean correlation; $\mathrm{SD} r=\operatorname{standard}$ deviation for $r ; \bar{\rho}=$ weighted correlation coefficient corrected for unreliability; SD $\bar{\rho}=$ standard deviation for $\bar{\rho} ; 95 \% \mathrm{CI}=95 \%$ confidence interval for $\bar{\rho} ; 80 \% \mathrm{CrI}=$

$80 \%$ credibility interval for $\bar{\rho}$; $\mathrm{NA}=$ Negative affect; $\mathrm{O}=$ Openness to Experience, $\mathrm{C}=$ Conscientiousness, $\mathrm{E}=\mathrm{Extraversion}, \mathrm{A}=\mathrm{Agreeableness,} \mathrm{N}$

$=$ Neuroticism; $\mathrm{WD}=$ workplace deviance; ${ }^{*} p<.05,{ }^{* *} p<.001$ 
Table 3

Total, indirect, and direct effects for all six tested meta-analytic mediation models

\begin{tabular}{llrrrrr}
\hline Mediator & \multicolumn{1}{c}{$N$} & \multicolumn{1}{c}{ Total Effect } & \multicolumn{1}{c}{ Indirect Effect } & \multicolumn{1}{c}{ Direct Effect } \\
\hline Negative Affect & 32 & 10,709 & $-.153(-.196,-.111)^{*}$ & $-.043(-.058,-.030)^{*}$ & $-.110(-.154,-.066)^{*}$ & Mediation \\
Openness to Experience & 20 & 5,425 & $-.104(-.163,-.044)^{*}$ & $-.002(-.008, .002)$ & $-.101(-.161,-.042)^{*}$ & No \\
Conscientiousness & 36 & 11,525 & $-.106(-.146,-.067)^{*}$ & $-.074(-.115,-.032)^{*}$ & $-.032(-.048,-.018)^{*}$ & Partial \\
Extraversion & 20 & 5,425 & $-.104(-.163,-.044)^{*}$ & $.002(-.003, .009)$ & $-.106(-.165,-.046)^{*}$ & No \\
Agreeableness & 24 & 8,243 & $-.116(-.158,-.074)^{*}$ & $-.025(-.041,-.010)^{*}$ & $-.092(-.135,-.048)^{*}$ & Partial \\
Neuroticism & 22 & 7,219 & $-.081(-.119,-.044)^{*}$ & $-.014(-.023,-.006)^{*}$ & $-.067(-.105,-.030)^{*}$ & Partial \\
\hline
\end{tabular}

Note. $k=$ cumulative number of studies; $N=$ cumulative sample size; Values in brackets are $95 \%$ confidence intervals, $* p<.05$. 
Figure 1

Figures

Personality traits as mediators for the relation between age and workplace deviance.

a)

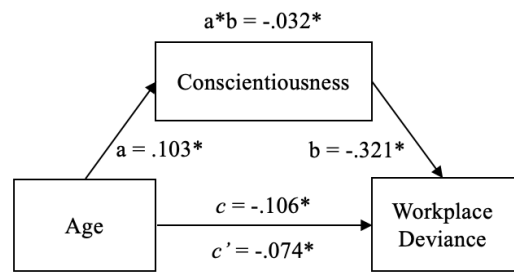

b)

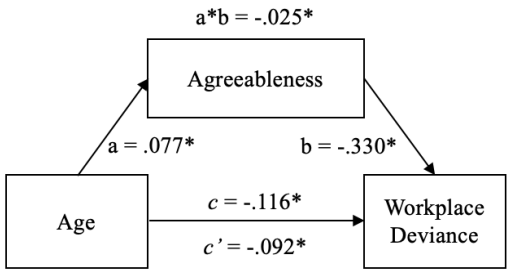

c)

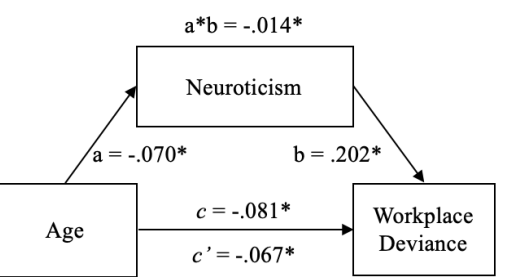

Note. a) Mediation model with conscientiousness, b) mediation model with agreeableness, c) mediation model with neuroticism, $\mathrm{a}=$ relation between age and mediator, $\mathrm{b}=$ relation between mediator and workplace deviance; $\mathrm{a}^{*} \mathrm{~b}=$ Indirect effect, $\mathrm{c}=$ total relation between age and workplace deviance, $\mathrm{c}^{\prime}=$ direct effect in the mediation model; $* p<.01$ 
Figure 2

Negative affect mediating the relation between age and workplace deviance.

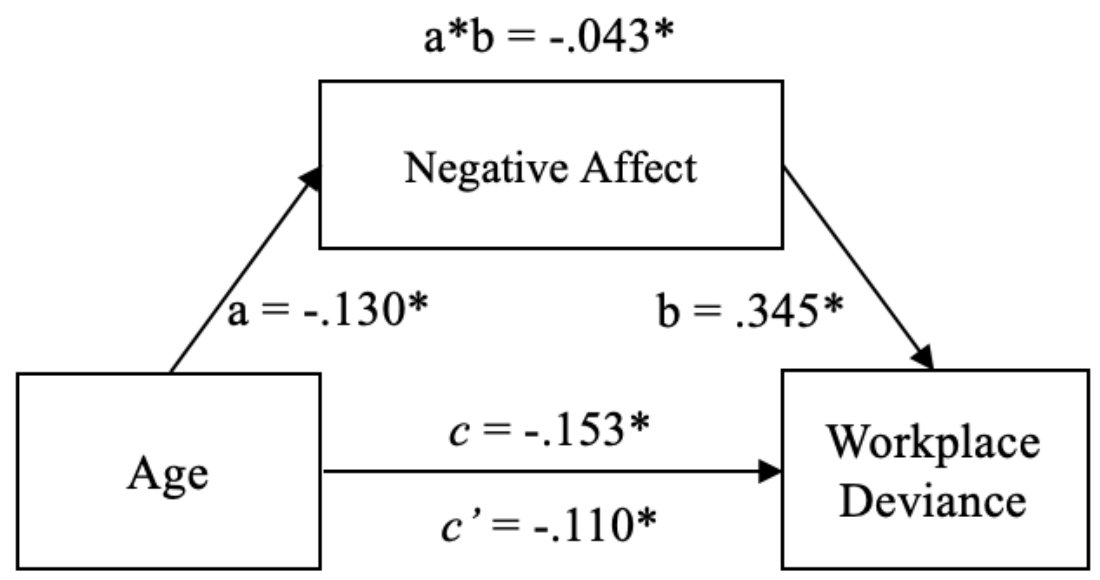

Note. $\mathrm{a}=$ relation between age and negative affect, $\mathrm{b}=$ relation between negative affect and workplace deviance; $\mathrm{a}^{*} \mathrm{~b}=$ indirect effect, $\mathrm{c}=$ total relation between age and workplace deviance, $\mathrm{c}^{\prime}=$ direct effect in the mediation model; ${ }^{*} p<.01$ 
Figure 3

Testing all Big five traits as mediators for the relation between age and workplace deviance

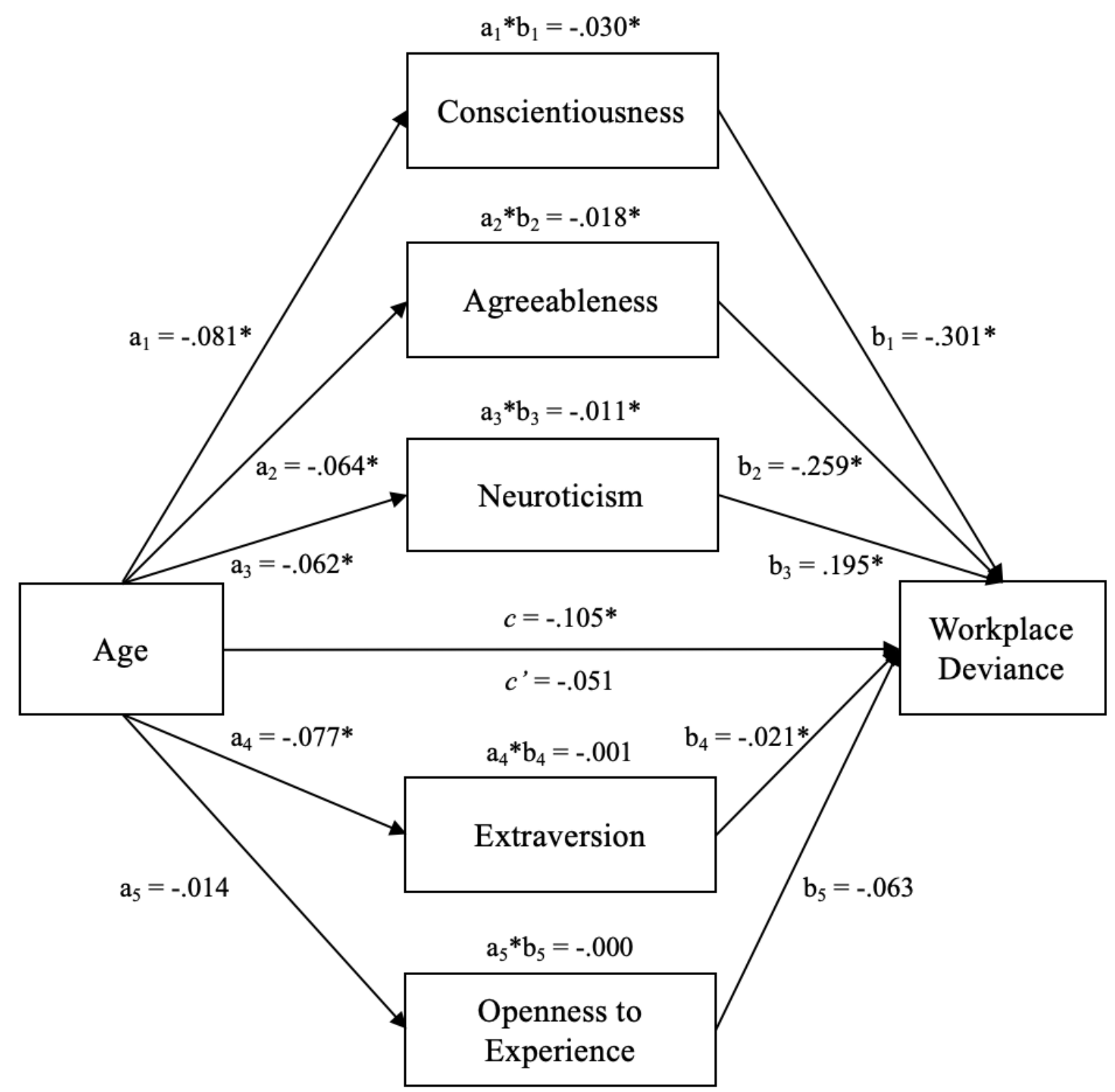

Note. $\mathrm{a}=$ relation between age and mediator, $\mathrm{b}=$ relation between mediator and workplace deviance; $\mathrm{a} * \mathrm{~b}=$ indirect effect, $\mathrm{c}=$ total relation between age and workplace deviance, $\mathrm{c}^{\prime}=$ direct effect in the mediation model; ${ }^{*} p<.05$ 


\section{Footnotes}

${ }^{1}$ Two forms of workplace deviance are commonly distinguished: interpersonal and organizational workplace deviance. The former describes deviant behavior directed toward other members of the organization, such as insulting a colleague or disobeying the supervisor's instructions. The latter characterizes deviant behavior targeting the organization, such as coming late to work or stealing from the employer. Both forms can vary in severity, but are always detrimental and costly for organizations (Henle et al., 2005; Sackett, 2002). ${ }^{2}$ For the relations between the Big Five personality traits and negative affect, we rely on effect size estimates from Anglim, Horwood, Smillie, Marrero, and Wood (2020). These estimates are: openness - negative affect $r=-.05, \bar{\rho}=-.06$; conscientiousness - negative affect $r=-.25, \bar{\rho}=-.29$; extraversion - negative affect $r=-.21, \bar{\rho}=-.24$; agreeableness negative affect $r=-.25, \bar{\rho}=-.30$; neuroticism - negative affect $r=.56, \bar{\rho}=.65$.

${ }^{3}$ This was only the case for 34 of the 509 coded effect sizes $(6.7 \%)$. For the MASEM, the percentage of studies that did not report reliabilities for the mediator and therefore had to be corrected using the average reliability across all other included studies ranged between $2.3 \%$ and $7.9 \%$.

${ }^{4}$ The rank correlation test could not be performed for overall workplace deviance because the underlying R function cannot handle such large number of studies.

${ }^{5}$ The overall conclusions remain the same when testing the mediation hypotheses with sample-size weighted correlations not corrected for unreliability. The conclusions also remain the same for both interpersonal and organizational workplace deviance. Detailed results can be found in the supplementary materials.

${ }^{6}$ The results remain qualitatively the same when only examining conscientiousness, agreeableness, neuroticism, and trait negative affect as mediators for the age-workplace deviance relation: All four personality traits then mediate the relation between age and workplace deviance, but the relation between age and workplace remains statistically 
significant (-.026; 95\% CI: -.049, -.003). The results also remain qualitatively the same when using observed correlations not corrected for unreliability instead of correlations corrected for unreliability. In addition, the results also largely remain the same for both interpersonal and organizational workplace deviance, with just two small exceptions for interpersonal workplace deviance. First, openness to experience (.002, 95\% CI: .000, .004) also significantly mediates the relation between age and interpersonal workplace deviance in the model with all Big Five traits and trait negative affect as mediators. Second, neuroticism no longer mediates the relation between age and interpersonal workplace deviance in a model in which only neuroticism and trait negative affect were entered as mediators. 